Karin de Boer

\title{
Kant's Account of Sensible Concepts in the Inaugural Dissertation and the Critique of Pure Reason
}

At one point in the Critique of Pure Reason Kant refers to the schemata of pure concepts as sensible concepts of an object. ${ }^{1}$ The only other text in which this term occurs is the Inaugural Dissertation. ${ }^{2}$ Evidently, the Dissertation discusses sensible cognition primarily in order to contrast it with purely intellectual cognition, the possibility of which Kant does not yet reject. Yet I hold that the relevance of his early account of sensible cognition extends well beyond the context in which it took root. The present paper aims to trace back Kant's account of the schematism of the pure understanding in the Critique of Pure Reason to the Dissertation. ${ }^{3}$ I will do so by discussing Kant's understanding of sensible cognition in view of his assessment of metaphysics. I will argue, first, that Kant in both texts aims to defend metaphysics against skeptical attacks by discarding those of its elements he considers unwarranted and, second, that this undertaking hinges on his account of concepts that function as the sensible condition of cognition. Yet whereas Kant argues in 1770 that metaphysics must be purely intellectual, he in 1781 draws on his earlier account of sensible concepts to argue, against the Wolffians, that determining intelligible objects by purely intellectual means does not amount to cognition proper. I thus hope to shed new light on an

1 Kant: KrV: A146/B186. I use the following translations: Critique of Pure Reason. Transl. and ed. Paul Guyer and Allan W. Wood. Cambridge 1998; Correspondence. Transl. and ed. Arnulf Zweig. Cambridge 1999; Theoretical Philosophy 1755-1770. Transl. and ed. David Walford. Cambridge 1992.

2 I will translate 'sensitivus' as 'sensible' rather than 'sensitive' because the German equivalent 'sinnlich' is normally translated as 'sensible'. Since the Dissertation does not yet clearly distinguish between the understanding and reason, I will translate 'intellectualis' as 'intellectual': what Kant calls intellectual concepts includes what he will come to call ideas of reason.

3 The only text I am aware of that deals with the schematism in relation to Kant's development between 1770 and 1781 is Wunsch, Matthias: Zum 'Schematismus' der reinen Verstandesbegriffe in Kants Inauguraldissertation von 1770. In: Kant und die Philosophie in weltbürgerlicher Absicht. Ed. Stefano Bacin, Alfredo Ferrarin, Claudio La Rocca, Margit Ruffing. Bd. 2. Berlin/Boston 2013, 505-516. Like the present article, Wunsch addresses Kant's view in the Dissertation that time functions as a sensible condition of cognition. Yet whereas he discusses the relevant passages in view of the role of intellectual concepts in experience (506), I do so by focusing on Kant's question as to the possibility of purely intellectual metaphysical cognition. 
element of both the Dissertation and the Schematism chapter that in my view has not been given its due.

\section{1}

In the Dissertation Kant aims to purge the intellectual cognition achieved in metaphysics of sensible concepts and principles that obscure their actual pedigree. ${ }^{4}$ As he sees it, metaphysics, containing "the first principles of the use of the pure intellect", ${ }^{5}$ has not yet detected the problems involved in this use, thus seriously hurting its credibility. Carrying out this propaedeutic task, as Kant proposes to do, ${ }^{6}$ requires an account of cognition that, contrary to Wolffian logic, focuses on the real rather than the logical use of the intellect. ${ }^{7}$ As Kant recalls, Wolff conceived of cognition in terms of the distinction between confused and distinct concepts. ${ }^{8}$ For a logic that reflects on this logical use of the intellect, the question as to the origin of concepts is of no regard. ${ }^{9}$

Though he is not very clear about this, Kant seems to conceive of the real use of the intellect as an activity geared toward things rather than mere concepts. Insofar as this activity is purely intellectual, determining things requires not so much the processing of representations given in intuition as the production of concepts and principles. In this case, Kant writes, the intellect proceeds by means of concepts "of objects as well as of their relations" that are given "through the nature of the intellect itself". ${ }^{10}$ As I see it, the term 'object' here can only refer to things, including the world as such, that are treated in rational cosmology and other parts of special metaphysics. Already in the Dissertation, Kant refers to these things as noumena. ${ }^{11}$ If this is the case, then the term 'relations' must refer to intellectual concepts such as substance, composition, and causality that articulate the relations in terms of which such things can be deter-

4 Kant: MSI, AA 02: 411.

5 Kant: MSI, AA 02: 395.

6 Kant: MSI, AA 02: 395.

7 The difficulty of the text is partly due to the entanglement of its two strands: a preparatory, second-order reflection on the perceived defects of rational cosmology and a first-order contribution to it. Examples of the latter strand can be found throughout the text, but especially in Section IV.

8 Kant: MSI, AA 02: $394 \mathrm{f}$.

9 Cf. Kant: MSI, AA 02: $410 \mathrm{f}$.

10 Kant: MSI, AA 02: 394, cf. 411.

11 Kant: MSI, AA 02: 396. 
mined. Seemingly independent of sensibility, the intellect in its real use purports to grasp the world insofar as it is intelligible, that is, such as it is in itself. ${ }^{12}$

As said, however, Kant holds that the real use of the intellect at stake in metaphysics calls for a critical inquiry into the origin of concepts because of its unacknowledged dependence on sensible concepts. Any cognition, Kant writes, "preserves the sign of its origin", which means, for instance, that "empirical concepts do not, in virtue of being raised to greater universality, become intellectual in the real sense", but "always remain sensible". ${ }^{13}$ Since geometry is called the "archetype" of sensible cognition, ${ }^{14}$ what Kant calls sensible concepts cannot refer to empirical concepts alone. It rather refers, I will argue, to any concept the meaning of which depends on a sensible condition. ${ }^{15}$

\section{2}

In order to analyze the real use of the intellect, Kant, as seen, more or less implicitly distinguishes between concepts that function as subject and concepts that function as predicate of a judgment. This distinction clearly corresponds to his later distinction between ideas of reason and pure concepts of the understanding. In the case of a truly intellectual judgment, an intellectual predicate such as composition or substance is attributed to an intellectual subject such as the world. This is the kind of judgment that according to Kant should make up a discipline such as rational cosmology. Yet while he notes that cognition is intellectual "insofar as it is subject to the laws of intelligence", ${ }^{16}$ he does not state that the metaphysics known to him actually consists of purely intellectual cognitions. This requires, as said, that it abandon the use of predicates that inconspicuously depend on sensibility.

In this regard, Kant distinguishes several cases. Thus, metaphysics can err by predicating empirical concepts such as 'somewhere' of all things, including mo-

12 Cf. Kant: MSI, AA 02: 387, 392. On this point I disagree with Sala, Giovanni B.: Der 'reale Verstandesgebrauch' in der Inauguraldissertation Kants von 1770. In: Kant-Studien, 69/1-4 (1978), 1-16. Sala first takes Kant to hold that the real use of the intellect results in "objective knowledge of reality" ( 3 , cf. $7 \mathrm{f}$.) and then complains that the full meaning of this escaped Kant himself (13).

13 Kant: MSI, AA 02: 394f.

14 Kant: MSI, AA 02: 394f.

15 Obviously, sensible concepts, like all concepts, are discursive as regards their form.

16 Kant: MSI, AA 02: 392. 
nads or the soul, whereas such concepts merely pertain to appearances. ${ }^{17}$ Metaphysics can also use properly intellectual concepts in a way that depends on sensibility, ${ }^{18}$ thus contaminating its principles in a less obvious way. For present purposes I will limit my discussion to the latter case.

The concepts that Kant considers to be genuinely intellectual include "possibility, existence, necessity, substance, cause, etc."19 The text suggests that quantity, the simple, composition, and totality also belong to this kind. ${ }^{20}$ Now I take Kant's point to be that such concepts acquire a different meaning depending on the way in which they are being used. Thus, the concept of quantity can be used in its capacity as a purely intellectual concept to posit that the world is limited as far as its magnitude is concerned..$^{21}$ According to Kant, however, this concept is often used in such a way that its meaning presupposes something that does not stem from the intellect at all, namely, time. In such cases metaphysicians represent the concept of quantity in terms of the act of adding one unity to another, ${ }^{22}$ an act which is conditioned by time considered as formal principle of intuition or pure intuition. ${ }^{23}$ Implicitly relying on the temporal meaning of quantity, they posit, for instance, the principle that "any real manifold can be expressed by a number". ${ }^{24}$ In this case, Kant writes, time serves

as a means for forming the concept of the predicate, thus affecting, as a condition, the intellectual concept of the subject, for it is only by relying on this condition that we can arrive at the latter concept. ${ }^{25}$

If metaphysicians implicitly determine quantity in terms of the act of adding one unity to the next, and attribute this sensible determination of quantity to the intellectual concept of a manifold, then the ensuing principle is not as purely intellectual as it purports to be. This is the case even though time is "contained" neither "in the concept of the predicate itself", that is, in the concept of quantity, nor in the concept of the subject, that is, the concept of a manifold. It is therefore not warranted to use the principle to infer, Kant notes, that a manifold such as

17 Kant: MSI, AA 02: 413f., cf. 419.

18 Kant: MSI, AA 02: 413.

19 Kant: MSI, AA 02: 395.

20 Kant: MSI, AA 02: 415, 387-388, 415-416.

21 Kant: MSI, AA 02: 416.

22 Kant: MSI, AA 02: 415, cf. 387.

23 Kant: MSI, AA 02: 396, 399.

24 Kant: MSI, AA 02: 415.

25 Kant: MSI, AA 02: 415, italics K.d.B. 
the world, "in respect of its mass, is mathematically finite". ${ }^{26}$ Similarly, he submits that it is warranted to posit that any body consists of simple elements, but not that it consists of a determinate number of simple elements. ${ }^{27}$ Such acts are subreptious because they introduce a heterogeneous predicate into the judgment - quantity in its capacity as sensible concept - while presenting it as purely intellectual. $^{28}$

Kant also explains this point in a different way. Insofar as metaphysics uses intellectual concepts by relying on a sensible condition, these concepts actually function as sensible concepts. Yet since sensible concepts merely pertain to the way in which the subject unifies representations, they cannot be used with regard to things as they are in themselves, that is, things such as they are grasped by the intellect (392). ${ }^{29}$ For Kant, a sensible predicate is nothing but a "condition of a possible sensible cognition", and therefore cannot be "stated objectively of an intellectual concept" - such as the concept of the world - that functions as the subject of the judgment. ${ }^{30}$

In sum, the new method Kant introduces into metaphysics ${ }^{31}$ consists in revealing that concepts such as causality or quantity, even though their content is purely intellectual, acquire a different meaning depending on whether or not their actual use presupposes time. To the extent that Wolffian metaphysics allows non-empirical, yet sensible predicates to encroach upon the real use of the intellect, it is prone to the thoroughgoing skepticism from which Kant tries to save what he believes deserves to be saved, namely, its purely intellectual core.

Now Kant does not claim that concepts that originate in the intellect can only be predicated of concepts that likewise originate in the intellect. Even though the Dissertation is primarily concerned with this issue, nothing indicates that he excludes the use of intellectual concepts in judgments that pertain to appearances qua possible objects of experience. ${ }^{32}$ As said, these concepts can be called sensible insofar as their use depends on time qua sensible condition. In this capacity, they give rise to "principles characteristic of sensible cognition". ${ }^{33}$ Thus, when the soul turns to experience, Kant writes, relations such as that between cause

26 Kant: MSI, AA 02: 415.

27 Kant: MSI, AA 02: 415f.

28 Kant: MSI, AA 02: 412f.

29 Kant: MSI, AA 02: 392.

30 Kant: MSI, AA 02: 412.

31 Kant: MSI, AA 02: 387, 411, 419.

32 Cf. Kant, Immanuel, on June 7, 1771 to Herz, Marcus (Kant: AA 10: 123).

33 Kant: MSI, AA 02: 411. 
and effect can only be known "with the assistance of the relation of time", because only in this way can it actually determine what precedes and what follows (406). ${ }^{34}$ This remark suggests that in this case it is warranted, and even necessary, to rely on time "as a means to form the concept of the predicate", that is, as the "condition" 35 that allows us, for instance, to predicate causality of appearances prior to experience. Thus, while Kant argues that this condition prevents metaphysics from adequately determining the world such as it is in itself, he implies that the mind has to rely on it in order to determine possible objects of experience in terms of substance, causality, quantity, etc.

\section{3}

It emerges from the Dissertation that Kant began to think about the sensible condition of cognition while reflecting on the limits within which metaphysics is possible. I do not think that the Critique differs from the Dissertation in this regard. However, Kant departs from his earlier position to argue, against both the Wolffians and the position he had defended in the Dissertation, that attributing a purely intellectual predicate to a purely intellectual concept of a subject does not amount to cognition proper. Abandoning part of the terrain to the skeptics, Kant somewhere between 1770 and 1781 must have realized that the act of determining things such as the world by means of purely intellectual concepts, severed from their sensible condition, is a matter of thought rather than cognition.

Kant's radicalization of his earlier critique of Wolffian metaphysics in the Critique rests on a number of elements that are lacking in the Dissertation, including the distinction between the understanding and reason, thought and cognition, and noumena in the negative and the positive sense. Yet in order to demonstrate that any a priori cognition of objects depends on a sensible cognition, as he does in the Schematism chapter, Kant could resort to his 1770 argument against the surreptitious use of sensible concepts in Wolffian metaphysics.

Invoking the language of the Dissertation, Kant presents this chapter as an investigation into "the sensible condition under which alone pure concepts of the understanding can be employed". ${ }^{36}$ As said, Kant in this context refers to schemata as sensible concepts. With regard to the use of sensible concepts in a priori cognition, the Dissertation implicitly distinguishes between geometrical

34 Kant: MSI, AA 02: 406.

35 Kant: MSI, AA 02: 415.

36 Kant: KrV, A136/B175. 
concepts and concepts that function as the sensible condition of the use of the intellect in metaphysics. Similarly, the Critique distinguishes between geometrical concepts and transcendental schemata. ${ }^{37}$

Drawing on the former to elucidate the latter, Kant considers the concept of a triangle to represent a rule for unifying a manifold, namely, three straight lines. While this rule can be grasped by the understanding, it can only be carried out by relying on space considered as pure intuition. This means that geometrical concepts, properly conceived, presuppose schemata. ${ }^{38}$ Analogously, a category, for Kant, "contains the function, unrestricted by any sensible condition", 39 which means that it is a purely intellectual rule for unifying a manifold. A transcendental schema, by contrast, is a "sensible condition" 40 that represents this very rule in a sensible way, which means that it tells the mind how to actually unify its successive representations. ${ }^{41}$ Insofar as they pertain to time, qua form of intuition, and determine the latter from within, ${ }^{42}$ schemata can be considered sensible. They can be considered intellectual, on the other hand, insofar as they represent the very functions that the categories, for their part, articulate in a purely intellectual way. ${ }^{43}$

Seen in this way, there is no reason to assume that, for Kant, schemata must somehow be added onto categories. ${ }^{44}$ I would submit that categories and schemata rather refer to two different ways in which a priori rules can be conceived, namely, the abstract way that underlies Wolffian metaphysics and, on the other hand, the way that, according to Kant, alone allows the mind to determine objects as extended, as persisting, as cause, as necessary, etc.

Accordingly, in order to count as cognition proper, even proofs of, for instance, the immortality of the soul, ought to rely on a determination of the concept of substance in terms of persistence, that is, on the schema of this concept. ${ }^{45}$

37 Kant: KrV, A140/B180.

38 Kant: KrV, A140f/B180.

39 Kant: $\mathrm{KrV}, \mathrm{A} 181 / \mathrm{B} 224$.

40 Kant: KrV, A147/B186.

41 Kant: KrV, A140/B179.

42 Kant: KrV, A139/B178.

43 Cf. Kant: KrV, A138/B177.

44 Drawing on the Duisburg Nachlass, Guyer argues in Kant and the Claims of Knowledge that Kant originally set out from the schemata and derived the categories from them. See Guyer, Paul: Kant and the Claims of Knowledge. Cambridge 1987, 175-176. While this is in agreement with my reading of the Dissertation, I disagree with Guyer's view that Kant in the Critique of Pure Reason retreats from this position because he here discusses categories prior to schemata.

45 Cf. Kant: KrV, A144/B183. 
For otherwise the rule at stake would lack a proper content and the mind would not know how to determine an object by means of it:

\begin{abstract}
Now if I say through mere category: 'the soul is a simple substance', then it is clear that, since the understanding's naked concept of substance contains nothing beyond the requirement that the thing be represented as a subject in itself without in turn being the predicate of another subject, nothing about persistence follows from this concept. ${ }^{46}$
\end{abstract}

Thus, Kant regards schemata no longer as infecting metaphysics, but rather as allowing it to obtain a priori cognition proper. Yet since schemata restrict the actual use of categories to possible objects of experience, cognition of noumena such as the soul is impossible:

\footnotetext{
Now if we leave out a restricting condition, it may seem as if [...] the categories in their pure significance, without any conditions of sensibility, obtained of things as such, as they are [...] and would therefore have a significance independent of all schemata [...]. [B]ut in this case no object and thus no significance is given to them that could yield a concept of the object. Thus, if one would leave out the sensible determination of persistence, substance would signify nothing more than a something that can be thought as a subject (without being a predicate of something else) [...]. Without schemata, therefore, the categories [...] do not represent any object. ${ }^{47}$
}

If passages such as these are read in light of the Dissertation, it cannot be maintained, as is commonly done, that the Schematism chapter is concerned with showing how we get from categories to appearances for the sake of empirical cognition. I hope to have shown, by contrast, that the aim of both the Dissertation and the Critique consists in preserving a space for metaphysics by revealing the inconspicuous role of pure, yet sensible concepts in a priori cognition. In 1770 Kant defended the core of Wolffian metaphysics by denouncing the dependence on sensible concepts of one of its layers. Pushing further, he in 1781 attacked this very core because of its independence of the very same concepts thus ultimately confining metaphysics to the a priori determination of possible objects of experience. ${ }^{48}$

46 Kant: $\operatorname{KrV}, \mathrm{A} 401$.

47 Kant: $K r V$, A146f, cf. A240-244/B300-302.

48 I would like to thank John Callanan, James Messina and Eric Watkins for their comments on earlier versions of this paper. 